\title{
MODEL TERINTEGRASI PENJADWALAN BATCH DAN PM DENGAN KRITERIA MINIMALISASI BIAYA SIMPAN, SETUP DAN PM PADA MESIN DENGAN INCREASING FAILURE RATE
}

\author{
Zahedi \\ Mathematics \& Statistics Department, School of Computer Science, Binus University \\ Jl. K.H. Syahdan No. 9, Palmerah, Jakarta Barat 11480 \\ zahedizahedi@binus.ac.id
}

\begin{abstract}
Development of today's manufacturing systems leads to the getting shorter in product life cycle, more variety of products, as well as increasing in consumer demand for quality and timeliness. Thus the accuracy and speed of decision-making within the manufacturing system becomes important. This paper proposes an integrated model of batch scheduling and preventive maintenance scheduling, in assumption no non-conforming parts to the criteria of minimizing the total saving cost, setup cost, preventive maintenance cost in minimizing the actual flow time on a machine with increasing failure rate. An example is provided to show how the model and algorithm work.
\end{abstract}

Keywords: batch scheduling, preventive maintenance scheduling, saving cost, setup cost, increasing failure rate

\begin{abstract}
ABSTRAK
Perkembangan sistem manufaktur dewasa ini mengarah pada siklus hidup produk yang semakin pendek, variasi produk yang semakin banyak, serta tuntutan konsumen terhadap kualitas dan ketepatan waktu penyerahan yang semakin tinggi. Dengan demikian ketepatan dan kecepatan pengambilan keputusan dalam sistem manufaktur menjadi penting. Makalah ini mengusulkan suatu model terintegrasi penjadwalan batch dan penjadwalan perawatan preventif dengan asumsi tidak ada part non conforming dengan kriteria minimasi total biaya simpan, biaya setup dan biaya preventive maintenance dalam kriteria penjadwalan minimasi waktu tinggal aktual pada mesin dengan increasing failure rate . Diberikan suatu contoh untuk memperlihatkan bagaimana model dan algoritma yang dikembangkan bekerja.
\end{abstract}

Kata kunci: penjadwalan batch, perawatan preventif, biaya simpan,biaya setup, increasing failure rate 


\section{PENDAHULUAN}

Dalam praktek, independensi penjadwalan produksi dan penjadwalan perawatan dapat menimbulkan beberapa kondisi sebagai berikut: Pertama, penjadwalan produksi yang tidak memperhatikan aspek perawatan akan menyebabkan mesin terus digunakan, padahal sudah saatnya menjalani perawatan. Bila perawatan tidak dilakukan akan berakibat mesin breakdown, sehingga akan mengganggu kegiatan produksi.Kedua, kegiatan perawatan yang tidak memperhatikan kegiatan produksi, sehingga saat mesin sibuk harus dihentikan untuk menjalani perawatan. Hal ini akan berakibat terganggunya jadwal produksi yang telah disusun sebelumnya

Penelitian-penelitian yang mengintegrasikan penjadwalan batch satu mesin dengan waktu perawatan probabilistik yang ditentukan dengan metoda optimisasi di antaranya Lee dan Rosenblat (1987), Wang dan Sheu (2001),Tseng (1996), Ben-Daya dan Noman (2006), Lin dan Hou (2005), Chelbi dkk (2008), Makhdoum (1996) serta El-Ferik dan Ben-Daya (2010). Lee dan Rosenblat (1987) membahas problem pengendalian bersama dari siklus produksi dengan perawatan mesin melalui inspeksi part yang dihasilkan mesin. Penelitian ini mengembangkan hubungan perawatan dan inspeksi dengan memperlihatkan bahwa selang inspeksi optimal adalah equally-spaced. Solusi simultan dari model adalah lot EMQ dan jadwal inspeksi yang diselesaikan dengan pendekatan fungsi biaya. Wang dan Sheu (2001) mengembangkan model gabungan untuk menentukan ukuran lot dan kebijakan inspeksi optimal untuk meminimasi ekspektasi biaya rata-rata per unit waktu dalam sistem produksi terdeteriorasi. Trade off antara production setup, inventory, inspeksi dan biaya kerusakan dianalisis dalam model ini untuk mendapatkan ukuran lot produksi dan inspeksi optimal. Tseng (1996) mengusulkan kebijakan optimal preventive maintenance untuk sistem produksi terdeteriorasi. Model kebijakan yang diusulkan melibatkan proses produksi yang mengalami deteriorasi dari status in control menjadi status out of control, jumlah item yang defect, serta mengoptimalkan biaya kerusakan yang meliputi biaya perbaikan, rework dan garansi. Ben-Daya dan Noman (2006) mengembangkan model terintegrasi yang memberikan keputusan tingkat inventory optimal, production run length dan jadwal preventive maintenance serta keputusan warranty secara simultan. Kriteria yang digunakan adalah maksimasi profit per unit produk, yaitu ekspektasi nilai revenue dikurang dengan ekspektasi biaya yang terdiri dari ekspektasi manufacturing cost, biaya PM dan inspeksi dan biaya warranty dan restorasi. Lin dan Hou (2005) mempelajari penentuan panjang selang produksi untuk model EMQ dengan proses produksi terdeteriorasi dan melibatkan biaya restorasi. Tujuan model adalah menemukan selang waktu optimal yang meminimasi total biaya per unit waktu yang terdiri dari biaya setup, biaya simpan, biaya restorasi dan biaya rework. Chelbi dkk (2008) mengusulkan model penentuan ukuran lot $\mathrm{Q}$ dan waktu $\mathrm{T}$ optimal untuk melaksanakan preventive maintenance berdasarkan umur mesin produksi yang mengalami deteriorasi. Sistem yang dibahas adalah satu mesin satu item dengan kriteria minimasi total rata-rata biaya per unit waktu dengan melibatkan inventory selama mesin dalam masa restorasi. Makhdoum (1996) mengembangkan model-model terintegrasi perawatan, kuantitas produksi, jadwal inspeksi dan disain peta kendali kualitas dengan berbagai kebijakan preventivemaintenance yang memanipulasi umur proses dan aktivitas PM menjadi lebih realistik. Sistem produksi yang diperhatikan adalah satu mesin satu item. Peta kendali rata-rata $x$ digunakan untuk memonitor proses produksi dan mempelajari pengaruh perawatan terhadap kualitas dan kuantitas produk yang dihasilkan. El-Ferik dan Ben-Daya (2010) membahas integrasi produksi dan perawatan, di mana waktu yang dibutuhkan untuk perawatan dan replacement tidak dapat diabaikan. Preventive maintenance yang diperhatikan adalah imperfect preventive maintenance, di mana produk cacat lebih banyak dihasilkan setelah suatu imperfect PM. Problemnya adalah menemukan panjang setiap production run dan banyak runs yang meminimisasi ekspektasi biaya total per unit waktu.

Makalah ini akan membahas pemodelan problem integrasi penjadwalan batch dan penjadwalan waktu preventive maintenance probabilistik dengan menggunakanpendekatan optimisasi 
dengan single item, single stage dan memperhitungkan holding cost, setup cost, preventive maintenance cost, serta waktu jatuh tempo (due date).

\section{METODE}

\section{Pengembangan Model}

Misalkan sekumpulan q part (satu order) dari item sejenis akan diproses pada sebuah mesin dengan ketaktersediaan mesin merupakan selang waktu PM. Waktu antar PM maksimum ditentukan dari machine availability dan hazard rate function. Setiap part hanya perlu satu operasi untuk menyelesaikannya (single stage). Dalam model awal ini diasumsikan mesin memenuhi distribusi kerusakan IFR Weibull.Semua part akan diserahkan pada waktu due date d.Tidak ada part yang nonconforming.PM-1 secara backward dilakukan pada saat due date untuk menjamin kondisi mesin as good as new pada order berikutnya.Permasalahan yang dibahas adalah menentukan ukuran-ukuran batch, jadwal batch, menentukan jumlah PM dan jadwal PM yang meminimasi biaya simpan, biaya setup dan biaya PM dalam kriteria penjadwalan waktu tinggal aktual. Parameter-parameter yang diketahui adalah:

$\mathrm{t}$ : waktu proses per part

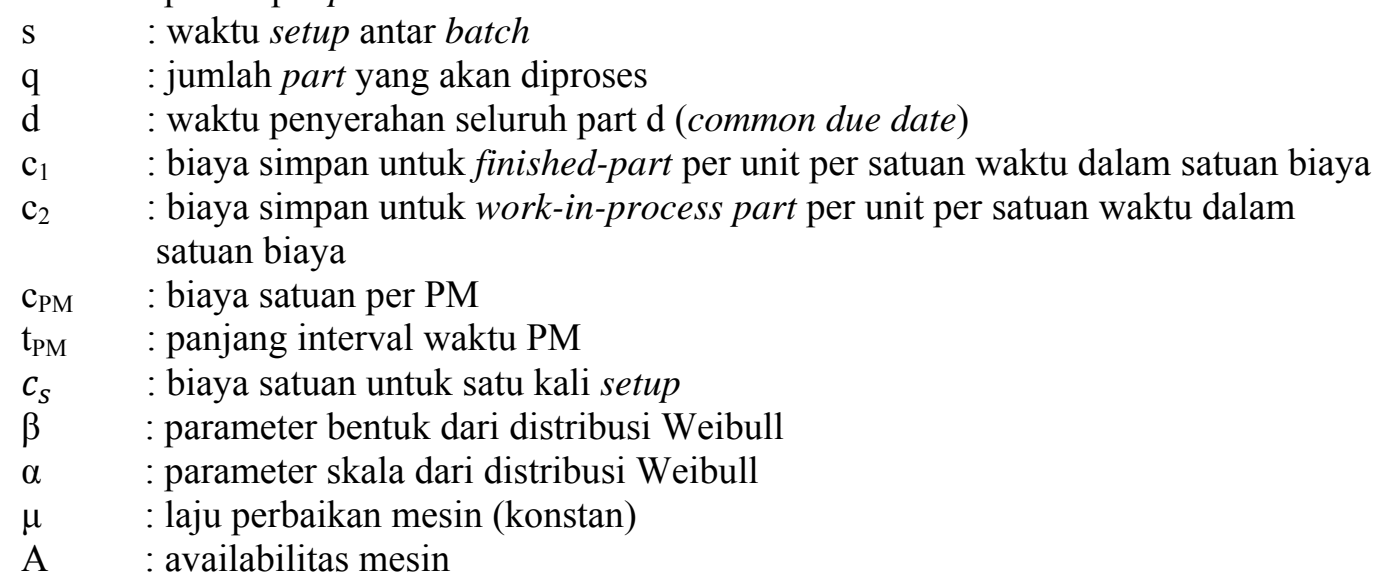

Variabel-variabel keputusan adalah

$\mathrm{L}_{[\mathrm{ik}]} \quad$ : batch yang dijadwalkan pada posisi ke-i dalam cycle ke-k (secara backward),

$\mathrm{i}=1,2, \ldots, \mathrm{N}_{\mathrm{k}(\max )}, \mathrm{k}=1,2, \ldots, \mathrm{g}$

$\mathrm{Q}_{[\mathrm{ik}]} \quad$ : ukuran batch $\mathrm{L}_{[\mathrm{ik}]}$ dalam unit

$\mathrm{N} \quad$ : jumlah seluruh batch

$\mathrm{B}_{[\mathrm{ik}]} \quad$ : saat mulai pemrosesan batch $\mathrm{L}_{[\mathrm{ik}]}$

$\mathrm{C}_{[\mathrm{ik}]} \quad$ : saat selesai batch $\mathrm{L}_{[\mathrm{ik}]}$

$\mathrm{A}_{\mathrm{PM}[\mathrm{k}]} \quad$ : saat awal PM ke-k

$\mathrm{B}_{\mathrm{PM}[\mathrm{k}]}$ : saat selesai PM ke-k

\section{Estimasi Panjang Interval PM Maksimum (Duarte dan Soares (2007)}

Ketersediaan (availability) mesin dalam kondisi steady state dapat ditulis sebagai $A \approx \frac{\mu}{\mu+\lambda}, \quad$ di mana A adalah availabilitas mesin steady state, $\mu$ adalah laju perbaikan konstan dan $\lambda$ adalah laju kerusakan konstan. 
Untuk menjamin nilai availabilitas A, diketahui laju perbaikan mesin konstan $\mu$, sehingga $\lambda$ dapat ditulis sebagai.

$$
\lambda \approx \frac{\mu(1-A)}{A}
$$
ratefunction

Misalkan mesin diketahui memiliki increasing failure rate Weibull dengan hazard

dan memiliki constant repair rate $\mu$.

$$
h(t)=\alpha \beta(\alpha t)^{\beta-1}, \beta>1, \alpha>0, \mathrm{t}>0
$$

Ide utama dari Duarte dan Soares (2007) adalah menentukan interval waktu PM maksimum dengan mensubstitusikan constant failure rate $\lambda$ pada increasing hazard rate $\mathrm{h}(\mathrm{t})$ untuk menjamin tingkat availabilitas yang telah ditetapkan sebelumnya (pre-determinate availability level). Asumsi yang digunakan adalah setelah setiap PM mesin menjadi as good as new. diperoleh.

Dengan teorema nilai rata-rata dalam kalkulus integral pada hazard rate function akan $x^{\beta-1}=\lambda \alpha^{-\beta}$,
maka $\mathrm{x}=0$ atau $x=\sqrt[\beta-1]{\lambda \alpha^{-\beta}}$.

$$
\begin{aligned}
& \int_{0}^{x} \alpha \beta(\alpha t)^{\beta-1} d t=\lambda x \\
& \Leftrightarrow \alpha^{\beta} \int_{0}^{x} \beta(t)^{\beta-1} d t=\lambda x \\
& \left.\Leftrightarrow \alpha^{\beta} t^{\beta}\right]_{0}^{x}=\lambda x \\
& \Leftrightarrow \alpha^{\beta} x^{\beta}=\lambda x \\
& x^{\beta-1}=\lambda \alpha^{-\beta}, \\
& \beta-1
\end{aligned}
$$

Substitusikan nilai estimasi $\lambda$ pada (1) pada (3) sehingga diperoleh

$$
x=\sqrt[\beta-1]{\frac{\mu(1-A)}{A} \alpha^{-\beta}} .
$$

Sehingga diperoleh panjang selang PM maksimum sebagai $[0, \mathrm{x}]$ atau

dengan hazard rate function

$$
\left[0, \sqrt[\beta-1]{\frac{\mu(1-A)}{A} \alpha^{-\beta}}\right],
$$

dan

$$
h(t)=\alpha \beta(\alpha t)^{\beta-1}
$$

$$
h(t)=\frac{\mu(1-A)}{A}
$$

Duarte dan Soares (2007) mengemukakan suatu proposisi sebagai berikut

Misal suatu system memenuhi increasing hazard rate $h(t)=\alpha \beta(\alpha t)^{\beta-1}$ dan constant repair rate $\mu$. Untuk menjamin ketersediaan system sama atau lebih besar dari A, panjang interval antar PM berurutan haruslah sama atau lebih kecil dari $\sqrt[\beta-1]{\frac{\mu(1-A)}{A} \alpha^{-\beta}}$.

\section{Pengembangan Biaya Simpan Indrapriatna (2009)}

Biaya simpan dalam Indrapriatna (2009) untuk satu production cycle adalah

$$
\mathrm{ToIC}=\mathrm{c}_{1} \sum_{i=1}^{N-1}\left\{\sum_{j=1}^{i}\left(t Q_{[j]}+s\right)\right\} Q_{i+1}+\frac{c_{1}+c_{2}}{2} t \sum_{i=1}^{N} Q_{[i]}^{2}+\frac{c_{2}-c_{1}}{2} t \sum_{i=1}^{N} Q_{[i]}
$$

Suku pertama dalam biaya simpan (6) adalah total biaya simpan part dalam completed batch dan suku kedua dan ketiga adalah total biaya simpan selama part diproses dalam batch (in process batch) dalam satu production cycle. 
Persamaan (6) dan Gambar (1) dari Indrapriatna (2009) akan dikembangkan menjadi formulasi biaya simpan untuk g production cycle dan menyisipkan selang PM secara simultan. Berikut akan diturunkan formulasi biaya simpan untuk 2, kemudian 3, selanjutnya akan digeneralisir untuk $\mathrm{g}$ production cycle. Jika dalam suatu production run terdapat g production cycle maka akan terdapat (g1) interval PM sepanjang production run dan PM terakhir dilakukan tepat saat due date (PM-1).

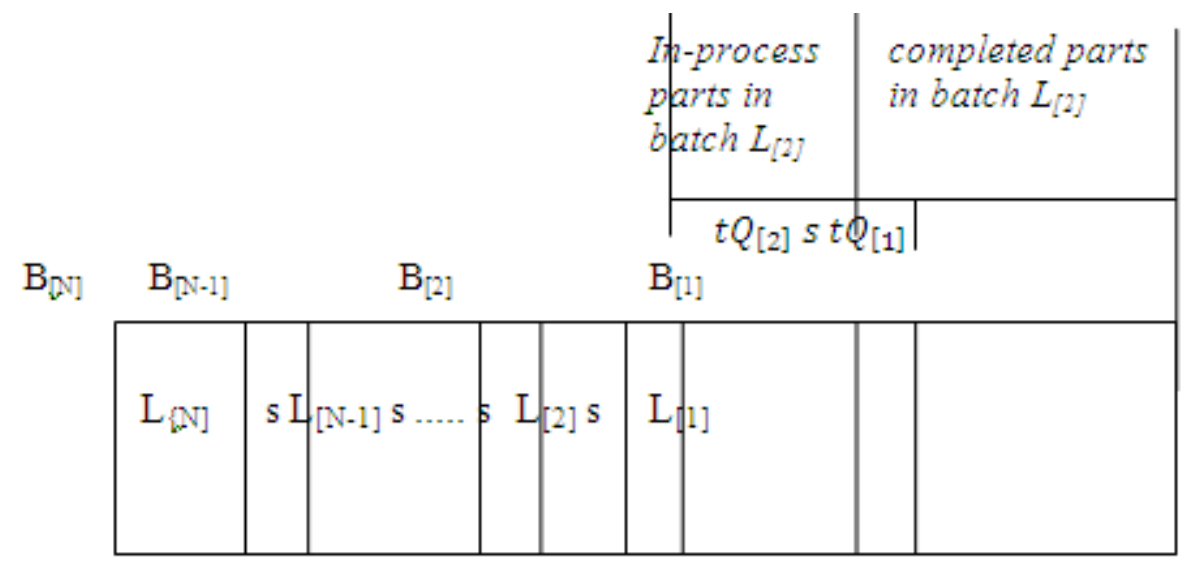

Gambar 1 Posisi batch dengan satu production cycle

\section{HASIL DAN PEMBAHASAN}

\section{Pengembangan Biaya Simpan untuk 2 Production Cycle}

Model konseptual dari penjadwalan batch dengan dua production cycle akan memiliki susunan batch sebagaimana Gambar 2 berikut.

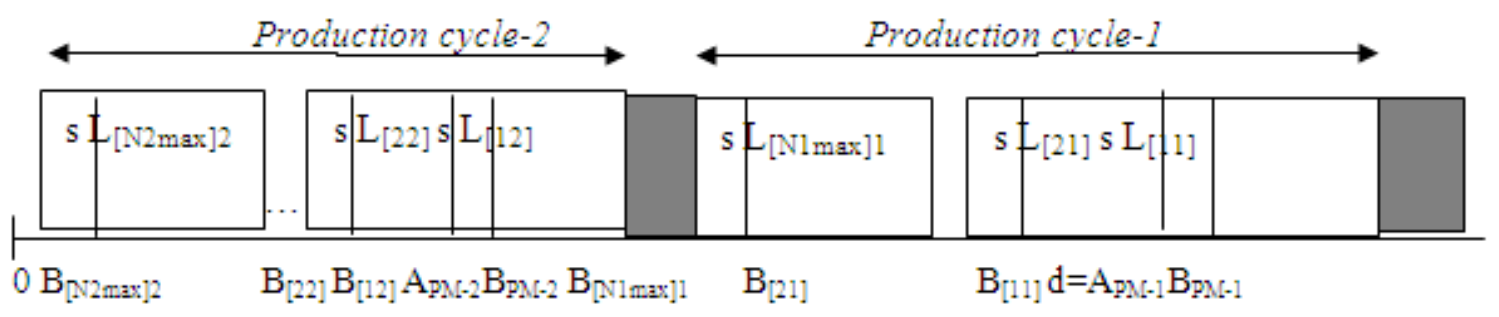

Selang PM

Gambar 2 Posisi batch dalam sistem manufaktur satu mesin dengan dua production cycle

Total biaya simpan untuk production cycle-1 adalah

$$
\begin{aligned}
\text { ToICcycle-1 } & =\mathrm{c}_{1} \sum_{i=1}^{N 1 \max -1}\left\{\sum_{j=1}^{i}\left(t Q_{[j 1]}+s\right)\right\} Q_{(i+1) 1} \\
& +\frac{c_{1}+c_{2}}{2} t \sum_{i=1}^{N 1 \max } Q_{[i 1]}^{2}+\frac{c_{2}-c_{1}}{2} t \sum_{i=1}^{N 1 \max } Q_{[i 1]}
\end{aligned}
$$

Total biaya simpan untuk production cycle-2 akan menjadi

ToICcycle-2

$$
\begin{aligned}
& =c_{1} \sum_{i=1}^{N 2 \max -1}\left\{\sum_{j=1}^{i}\left(t Q_{[j 2]}+s\right)\right\} Q_{(i+1) 2} \\
& +\frac{c_{1}+c_{2}}{2} t \sum_{i=1}^{N 2 \max } Q_{[i 2]}^{2}+\frac{c_{2}-c_{1}}{2} t \sum_{i=1}^{N 2 \max } Q_{[i 2]} \\
& +c_{1} \sum_{i=1}^{N 2 \max } Q_{[i 2]}\left(t_{P M}+\sum_{i=1}^{N 1 \max }\left(t Q_{[j 1]}+s\right)\right.
\end{aligned}
$$


Suku terakhir dalam persamaan (8) adalah waktu tambahan untuk semua completed batch dalam production cycle ke-2 menunggu sampai saat penyerahan $\mathrm{d}$. Sehingga Total biaya simpan untuk kedua production cycle adalah penjumlahan persamaan (7) dan (8) sebagai

$$
\begin{aligned}
& \operatorname{ToIC}(2)=\mathrm{c}_{1} \sum_{i=1}^{N 1 \max -1}\left\{\sum_{j=1}^{i}\left(t Q_{[j 1]}+s\right)\right\} Q_{(i+1) 1}+\frac{c_{1}+c_{2}}{2} t \sum_{i=1}^{N 1 \max } Q_{[i 1]}^{2}+\frac{c_{2}-c_{1}}{2} t \sum_{i=1}^{N 1 \max } Q_{[i 1]} \\
& +\mathrm{c}_{1} \sum_{i=1}^{N 2 \max }-1\left\{\sum_{j=1}^{i}\left(t Q_{[j 2]}+s\right)\right\} Q_{(i+1) 2}+\frac{c_{1}+c_{2}}{2} t \sum_{i=1}^{N 2 \max } Q_{[i 2]}^{2}+\frac{c_{2}-c_{1}}{2} t \sum_{i=1}^{N 2 \max } Q_{[i 2]} \\
& +c_{1} \sum_{i=1}^{N 2 \max } Q_{[i 2]}\left(t_{P M}+\sum_{i=0}^{N 1 \max }\left(t Q_{[j 1]}+s\right)\right.
\end{aligned}
$$

\section{Biaya Simpan untuk 3 Production Cycle}

Model konseptual dari penjadwalan batch dengan tiga production cycle akan memiliki susunan batch sebagaimana Gambar 3 berikut.

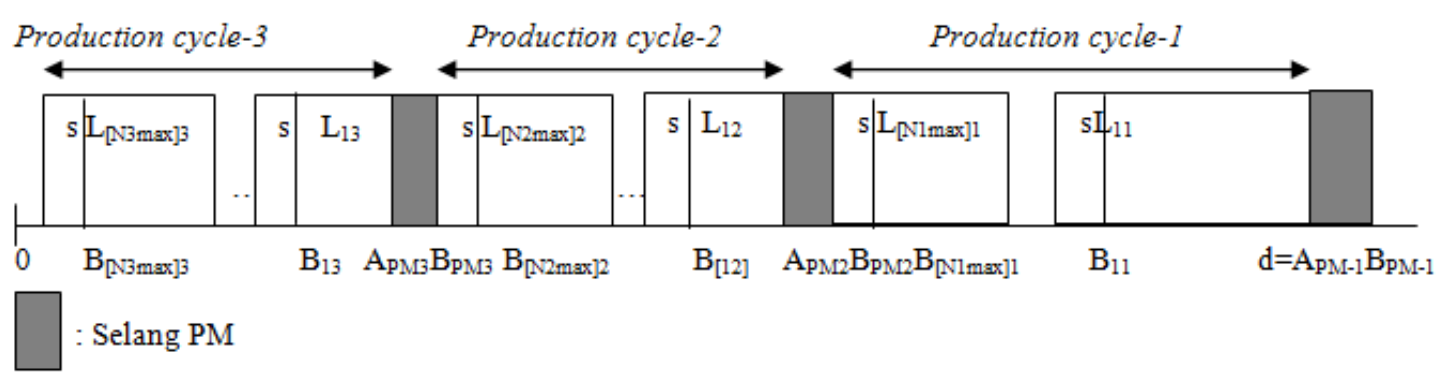

Gambar 3 Posisi batch dalam sistem manufaktur satu mesin dengan tiga production cycle

Total biaya simpan untuk production cycle -1 adalah

$$
\begin{aligned}
\text { ToICcycle-1 } & =\mathrm{c}_{1} \sum_{i=1}^{N 1 \max -1}\left\{\sum_{j=1}^{i}\left(t Q_{[j 1]}+s\right)\right\} Q_{(i+1) 1} \\
& +\frac{c_{1}+c_{2}}{2} t \sum_{i=1}^{N 1 \max } Q_{[i 1]}^{2}+\frac{c_{2}-c_{1}}{2} t \sum_{i=1}^{N 1 \max } Q_{[i 1]}
\end{aligned}
$$

Total biaya simpan untuk production cycle -2 akan menjadi

$$
\begin{aligned}
\text { ToICcycle-2 } & =\mathrm{c}_{1} \sum_{i=1}^{N 2 \max -1}\left\{\sum_{j=1}^{i}\left(t Q_{[j 2]}+s\right)\right\} Q_{(i+1) 2} \\
& +\frac{c_{1}+c_{2}}{2} t \sum_{i=1}^{N 2 \max } Q_{[i 2]}^{2}+\frac{c_{2}-c_{1}}{2} t \sum_{i=1}^{N 2 \max } Q_{[i 2]} \\
& +c_{1} \sum_{i=1}^{N 2 \max } Q_{[i 2]}\left(t_{P M}+\sum_{i=0}^{N 1 \max }\left(t Q_{[j 1]}+s\right)\right.
\end{aligned}
$$

Total biaya simpan untuk production cycle-3 akan menjadi

$$
\begin{aligned}
\text { ToICcycle-3 }= & \mathrm{c}_{1} \sum_{i=1}^{N 3 \max -1}\left\{\sum_{j=1}^{i}\left(t Q_{[j 3]}+s\right)\right\} Q_{(i+1) 3} \\
& +\frac{c_{1}+c_{2}}{2} t \sum_{i=1}^{N 3 \max } Q_{[i 3]}^{2}+\frac{c_{2}-c_{1}}{2} t \sum_{i=1}^{N 3 \max } Q_{[i 3]} \\
& +c_{1} \sum_{i=1}^{N 3 \max } Q_{[i 3]}\left(2 t_{P M}+\sum_{i=0}^{N 1 \max }\left(t Q_{[j 1]}+s\right)+\sum_{i=1}^{N 2 \max }\left(t Q_{[j 2]}+s\right)\right.
\end{aligned}
$$

Suku terakhir dalam persamaan (12) adalah waktu tambahan untuk semua completed batch dalam production cycle ke-3 menunggu sampai saat penyerahan $\mathrm{d}$. Sehingga Total biaya simpan untuk ketigaproduction cycle adalah penjumlahan persamaan (10), (11) dan (12) sebagai

$$
\begin{aligned}
& \operatorname{ToIC}(3)=\mathrm{c}_{1} \sum_{i=1}^{N 1 \max -1}\left\{\sum_{j=1}^{i}\left(t Q_{[j 1]}+s\right)\right\} Q_{(i+1) 1}+\frac{c_{1}+c_{2}}{2} t \sum_{i=1}^{N 1 \max } Q_{[i 1]}^{2}+\frac{c_{2}-c_{1}}{2} t \sum_{i=1}^{N 1 \max } Q_{[i 1]^{+}} \\
& \mathrm{c}_{1} \sum_{i=1}^{N 2 \max -1}\left\{\sum_{j=1}^{i}\left(t Q_{[j 2]}+s\right)\right\} Q_{(i+1) 2}+\frac{c_{1}+c_{2}}{2} t \sum_{i=1}^{N 2 \max } Q_{[i 2]}^{2}+\frac{c_{2}-c_{1}}{2} t \sum_{i=1}^{N 2 \max } Q_{[i 2]} \\
& +c_{1} \sum_{i=1}^{N 2 \max } Q_{[i 2]}\left(t_{P M}+\sum_{i=0}^{N 1 \max }\left(t Q_{[j 1]}+s\right)+\mathrm{c}_{1} \sum_{i=1}^{N 3 \max -1}\left\{\sum_{j=1}^{i}\left(t Q_{[j 3]}+s\right)\right\} Q_{(i+1) 3}\right. \\
& +\frac{c_{1}+c_{2}}{2} t \sum_{i=1}^{N 3 \max } Q_{[i 3]}^{2}+\frac{c_{2}-c_{1}}{2} t \sum_{i=1}^{N \max } Q_{[i 3]}+ \\
& c_{1} \sum_{i=1}^{N 3 \max } Q_{[i 3]}\left(2 t_{P M}+\sum_{i=0}^{N 1 \max }\left(t Q_{[j 1]}+s\right)+\sum_{i=1}^{N 2 \max }\left(t Q_{[j 2]}+s\right)\right.
\end{aligned}
$$

Dengan memperhatikan perubahan yang terjadi untuk setiap production cycle dan jumlah PM maka untuk g production cycle dan g-1 selang PM Total biaya simpan adalah 


$$
\begin{aligned}
& \operatorname{ToIC}(\mathrm{g})=\mathrm{c}_{1} \sum_{i=1}^{N 1 \max -1}\left\{\sum_{j=1}^{i}\left(t Q_{[j 1]}+s\right)\right\} Q_{(i+1) 1} \\
& +\frac{c_{1}+c_{2}}{2} t \sum_{i=1}^{N 1 \max } Q_{[i 1]}^{2}+\frac{c_{2}-c_{1}}{2} t \sum_{i=1}^{N 1 \max } Q_{[i 1]}+\sum_{k=2}^{g}\left[\mathrm{c}_{1} \sum_{i=1}^{N k m a x}-1\left\{\sum_{j=1}^{i}\left(t Q_{[j k]}+s\right)\right\} Q_{(i+1) k^{+}}\right. \\
& \left.\left.\frac{c_{1}+c_{2}}{2} t \sum_{i=1}^{N k m a x} Q_{[i k]}^{2}+\frac{c_{2}-c_{1}}{2} t \sum_{i=1}^{N k m a x} Q_{[i k]}\right)+c_{1} \sum_{i=1}^{N k m a x} Q_{[i k]}(k-1) t_{P M}+\sum_{i=1}^{N(k-1) \max }\left(t Q_{[j k]}+s\right)\right]
\end{aligned}
$$

\section{Biaya PM}

Untuk biaya PM sepanjang production run, dengan g production cycle dan g PM adalah

$$
\mathrm{TCPM}=\mathrm{g} \mathrm{c}_{\mathrm{PM}}
$$

\section{Biaya Setup} atau ditulis

Untuk total biaya setup adalah jumlah jumlah total batch dikalikan dengan biaya satuan setup,

$$
\mathrm{TCS}=c_{S} \sum_{k=1}^{g} N_{k(\max )}
$$

Fungsi tujuan yang akan digunakan adalah minimasi total biaya simpan, biaya PM dan biaya setup (TCS)dapat dirumuskan sebagai minimasi persamaan (14), (15) dan (16) atau

$$
\text { Minimai } \mathrm{TC}=\mathrm{ToIC}(\mathrm{g})+\mathrm{TCPM}+\mathrm{TCS}
$$

Beberapa kendala pada problem penjadwalan satu item satu mesin dengan ginterval PM dapat diuraikan sebagai berikut:

1. Keseimbangan jumlah part dalam semua batch akan sama dengan jumlah keseluruhan part yang dijadwal, dengan asumsi proses sempurna tanpa kerusakan, dirumuskan sebagai jumlah dari jumlah part dalam batch ke-i pada production cycle ke-k atau

$\sum_{k=1}^{g} \sum_{i=1}^{N_{k(\max )}} Q_{i k}=q$

2. Setiap batch terjadwal diasumsikan datang tepat pada saat akan diproses dan harus rapat ke due date, atau dapat ditulis sebagai dua persamaan berturut-turut untuk production cycle pertama (19) dan untuk production cycle kedua dan selanjutnya (20)

$$
\begin{gathered}
B_{i 1}+\sum_{i=1}^{N 1(\max )}\left(s X_{i 1}+t Q_{i 1}\right)-s=d, k=1 \\
B_{i k}+\sum_{l=1}^{k}\left[\sum_{j=1}^{i}\left(s X_{j l}+t Q_{j l}+(k-1) t_{P M}\right)\right]-s+\sum_{i=1}^{N 1(\max )}\left(s X_{i 1}+t Q_{i 1}\right)=d, \\
i=1,2, \ldots, N k(\max ) \text { dan } k=2,3, \ldots, g
\end{gathered}
$$

3. Untuk pengaturan sequencing antar batch akan digunakan variable biner $Y_{i j}^{k l}$ yang bernilai 0 atau 1, di mana $Y_{i j}^{k l}$ bernilai 1 apabila batch ke-i pada production cycle-j mendahului batch ke$\mathrm{k}$ pada production cycle ke-1 secara backward, dan bernilai 0 untuk sebaliknya. Untuk semua batch terjadwal dapat dirumuskan sebagai

$$
B_{i j}+t Q_{i j} \leq B_{(i+1) j}+M Y_{i j}^{(i+1) j}, i=1,2, \ldots,\left(N_{i(\max )}-1\right), j=1,2,3, \ldots, g
$$


Di mana $\mathrm{M}$ adalah suatu bilangan yang cukup besar untuk menjamin sequencing, dalam prakteknya dapat diambil $\mathrm{M}=\mathrm{q}(\mathrm{s}+\mathrm{t})$.

4. Kendala panjang interval PM untuk setiap selang antar PM

$$
\sum_{i=0}^{N k(\max )}\left(t Q_{[i k]}+s\right) \leq \sqrt[\beta-1]{\frac{\mu(1-A)}{A} \alpha^{-\beta}}, k=1,2, \ldots, g
$$

5. Metoda PM menggunakan regular PM, di mana interval waktu PM maksimum mengikuti persamaan (5), di mana waktu nol pada persamaan (5) adalah waktu mulai pekerjaan batch awal dari setiap interval antar PM atau setiap $\mathrm{B}_{[\mathrm{Nkmax}] \mathrm{k}}$ dengan $\mathrm{k}=1,2, \ldots, \mathrm{g}$, karena asumsi setelah setiap PM mesin menjadi as good as new. PM-1 terjadwal atau PM terakhir dilakukan setelah semua batch selesai diproses, sehingga dapat ditulis untuk 2 production cycle dengan 2 interval PM.

$\mathrm{A}_{\mathrm{PM}-1}=\mathrm{B}_{11}+\mathrm{t} \mathrm{Q}_{11}$

$\mathrm{A}_{\mathrm{PM}-1}=\mathrm{d}$

$\mathrm{B}_{\mathrm{PM}-1}=\mathrm{A}_{\mathrm{PM}-1}+\mathrm{t}_{\mathrm{PM}}$, selanjutnya

$\mathrm{A}_{\mathrm{PM}-2}=\mathrm{B}_{12}+\mathrm{t} \mathrm{Q}_{12}$

$\mathrm{B}_{\mathrm{PM}-2}=\mathrm{A}_{\mathrm{PM}-2}+\mathrm{t}_{\mathrm{PM}}$

$\mathrm{A}_{\mathrm{PM}-2}+\frac{1}{2} t_{P M}=\left(B_{[N 2 \max ] 2}-s\right)+\frac{d-\left(B_{[N 2 \max ] 2}-s\right)}{2}$.

3 production cycle dengan 3 interval $\mathrm{PM}$

$\mathrm{A}_{\mathrm{PM}-1}=\mathrm{B}_{11}+\mathrm{t} \mathrm{Q}_{11}$

$\mathrm{A}_{\mathrm{PM}-1}=\mathrm{d}$

$\mathrm{B}_{\mathrm{PM}-1}=\mathrm{A}_{\mathrm{PM}-1}+\mathrm{t}_{\mathrm{PM}}$, selanjutnya

$\mathrm{A}_{\mathrm{PM}-2}=\mathrm{B}_{12}+\mathrm{t} \mathrm{Q}_{12}$

$\mathrm{B}_{\mathrm{PM}-2}=\mathrm{A}_{\mathrm{PM}-2}+\mathrm{t}_{\mathrm{PM}}$

$\mathrm{A}_{\mathrm{PM}-2}+\frac{1}{2} t_{P M}=\left(B_{[N 3 \max ] 3}-s\right)+\frac{2}{3}\left(d-\left(B_{[N 3 \max ] 3}-s\right)\right)$, selanjutnya

$\mathrm{A}_{\mathrm{PM}-3}=\mathrm{B}_{13}+\mathrm{t} \mathrm{Q}_{13}$

$\mathrm{B}_{\mathrm{PM}-3}=\mathrm{A}_{\mathrm{PM}-3}+\mathrm{t}_{\mathrm{PM}}$

$\mathrm{A}_{\mathrm{PM}-3}+\frac{1}{2} t_{P M}=\left(B_{[N 3 \max ] 3}-s\right)+\frac{1}{3}\left(d-\left(B_{[N 3 \max ] 3}-s\right)\right)$

Generalisasi untuk $\mathrm{g}$ production cycle dengan $\mathrm{g}$ interval $\mathrm{PM}$ adalah

$\mathrm{A}_{\mathrm{PM}-1}=\mathrm{B}_{11}+\mathrm{t} \mathrm{Q}_{11}$

$\mathrm{A}_{\mathrm{PM}-1}=\mathrm{d}$

$\mathrm{B}_{\mathrm{PM}-1}=\mathrm{A}_{\mathrm{PM}-1}+\mathrm{t}_{\mathrm{PM}}$, selanjutnya

$\mathrm{A}_{\mathrm{PM}-2}=\mathrm{B}_{12}+\mathrm{t} \mathrm{Q}_{12}$

$\mathrm{B}_{\mathrm{PM}-2}=\mathrm{A}_{\mathrm{PM}-2}+\mathrm{t}_{\mathrm{PM}}$

$\mathrm{A}_{\mathrm{PM}-2}+\frac{1}{2} t_{P M}=\left(B_{[\text {Ngmax }] g}-s\right)+\frac{g-1}{g}\left(d-\left(B_{[\text {Ngmax }] g}-s\right)\right)$, selanjutnya

$\cdots$

$\mathrm{A}_{\mathrm{PM}-\mathrm{g}}=\mathrm{B}_{1 \mathrm{~g}}+\mathrm{t} \mathrm{Q}_{1 \mathrm{~g}}$

$\mathrm{B}_{\mathrm{PM}-\mathrm{g}}=\mathrm{A}_{\mathrm{PM}-\mathrm{g}}+\mathrm{t}_{\mathrm{PM}}$

$\mathrm{A}_{\mathrm{PM}-\mathrm{g}}+\frac{1}{2} t_{P M}=\left(B_{[\text {Ngmax }] g}-s\right)+\frac{1}{g}\left(d-\left(B_{[\text {Ngmax }] g}-s\right)\right)$

6. Jumlah batch maksimum dihitung dengan persamaan

$\left(N_{(\max )}-1\right) s+t q \leq d$

Dengan demikian $\mathrm{N}_{\max }=\left\lfloor\frac{d-t q}{s}+1\right\rfloor$

7. Dibutuhkan juga syarat-syarat kenonnegatifan variabel keputusan dan variabel biner sebagai 


$$
\begin{aligned}
& Y_{i k}^{j l}+Y_{j l}^{i k}=1, \mathrm{i}, \mathrm{j}=1,2, \ldots, \mathrm{N}_{\mathrm{k}(\max )}, \mathrm{k}, 1=1,2, \ldots, \mathrm{g}, \mathrm{ik} \neq \mathrm{j} 1 \\
& Q_{i j} \geq 0, \mathrm{i}=1,2, \ldots, \mathrm{N}_{\mathrm{k}(\max )}, \mathrm{j}=1,2, \ldots, \mathrm{g} \\
& Q_{i j} \leq X_{i j} \mathrm{q}, \mathrm{i}=1,2, \ldots, \mathrm{N}_{\mathrm{k}(\max )}, \mathrm{j}=1,2, \ldots, \mathrm{g} \\
& N_{k(\max )} \geq 1, \mathrm{k}=1,2, \ldots, \mathrm{g}
\end{aligned}
$$

\section{Model}

Model satu item satu mesin dengan g production cycle dengan g interval PM dengan kriteria minimasi biaya simpan, biaya PM dan biaya setupserta biaya rework dapat ditulis sebagai

Kendala

$$
\text { Minimasi TC }=\text { ToIC }+\mathrm{TCPM}+\mathrm{TCS}
$$

$$
\begin{aligned}
& \sum_{k=1}^{g} \sum_{i=1}^{N_{k(\max )}} Q_{i k}=q \quad(30) \\
& B_{i 1}+\sum_{i=1}^{N 1(\max )}\left(s X_{i 1}+t Q_{i 1}\right)-s=d, k=1 \\
& B_{i k}+\sum_{l=1}^{k}\left[\sum_{j=1}^{i}\left(s X_{j l}+t Q_{j l}+(k-1) t_{P M}\right)\right]-s+\sum_{i=1}^{N 1(\max )}\left(s X_{i 1}+t Q_{i 1}\right)=d, \\
& \quad i=1,2, \ldots, N k(\max ) d a n k=2,3, \ldots, g
\end{aligned}
$$

Persamaan (29) adalah minimasi fungsi tujuan meliputi minimasi total biaya simpan, total biaya PM dan total biaya setup (TCS). Kendala persamaan (30) menyatakan keseimbangan jumlah total part dalam semua batchakan sama dengan jumlah keseluruhan part yang dijadwal, dengan asumsi proses sempurna tanpa kerusakan. Kendala persamaan (31) dan (32) masing-masing menyatakan setiap batch terjadwal harus rapat ke due date untuk production cycle pertama (31), dan production cycle setelah yang pertama di mana terdapat interval PM (32). Pertaksamaan (33) menyatakan urutan dua batch, di mana suatu batch harus mendahului yang lain, nilai $\mathrm{M}$ adalah 
bilangan positif yang cukup besar, di mana $Y_{i k}^{(i+1) k}=1$ akan berakibat batch-ik akan mendahului batch-(i+1)k secara backward dan $Y_{i k}^{(i+1) k}=0$ untuk yang lain. Pertaksamaan (34) menyatakan jumlah waktu untuk setiap production cycle harus lebih kecil atau sama dengan interval maksimum antar dua PM (Duarte dan Soares (2007)). Persamaan (35) menyatakan waktu awal dan berakhirnya regular PM untuk setiap production cycle. Pertaksamaan (36) menyatakan jumlah waktu proses semua part termasuk waktu setup antar batch kecuali setupbatch pertama yang diproses, harus lebih kecil atau sama dengan due date. Persamaan (37) adalah kendala binary, di mana suatu batch mendahului atau didahului oleh batchlain dan tidak mungkin dua batch dirposes di shop pada saat bersamaan. Pertaksamaan (38) dan (39) masing-masing menyatakan syarat kenonnegatifan ukuran batch dan ukuran batch harus lebih kecil atau sama dengan ukuran order. Pertaksamaan (40) menyatakan jumlah batch minimal adalah satu. dioperasikan.

Untuk menyelesaikan model ini dirancang suatu algoritma sehingga model ini dapat

\section{Algoritma Model}

Step-1. Hitung $\mathrm{T}_{\min }=\mathrm{q} . \mathrm{t}$

Step-2. Problem layak jika dan hanya jika $\mathrm{T}_{\min }+(\mathrm{g}-1) t_{P M} \leq \mathrm{d}$. Lanjutkan Step-3. Jika $\mathrm{T}_{\min }+t_{P M}>\mathrm{d}$, maka problem tidak layak, stop.

Step-3. Hitung N(max) dengan persamaan (36).

Step-4. Hitung panjang selang PM maksimum $x$ dengan persamaan (5)

Step-5. Set $\mathrm{k}=1$ (! kproduction cycle dengan $\mathrm{k}$ PM)

Step-6. Substitusikan nilai-nilai dari $\mathrm{N}$ dengan $\mathrm{N}=\left\lfloor\mathrm{N}_{\text {maks }}\right\rfloor, \mathrm{p}, \mathrm{q}, \mathrm{t}, \mathrm{s}, \mathrm{d}, t_{P M}$, dan $\mathrm{x}$ ke dalam model.

Step-7. Set $Y_{i k}^{j l}=1$, jika ikmendahuluijl secara backward, $\forall \mathrm{i}, \mathrm{j}, \mathrm{k}, 1, \mathrm{ik} \neq \mathrm{jl}$, dan $Y_{i k}^{j l}=0$ untuk yang lainnya.

Step-8. Set $\mathrm{TC}_{(0)}=\mathrm{q}\left(\mathrm{c}_{1}+\mathrm{c}_{2}+\mathrm{c}_{\mathrm{PM}}+\mathrm{c}_{\mathrm{s}}\right)$

Step-9. Set $\mathrm{i}=1, \mathrm{j}=\mathrm{k}$, set $\mathrm{X}_{\mathrm{ij}}=1$, dan $\mathrm{X}_{\mathrm{ij}}=0$ untuk yang lain.

Step-10. Selesaikan Model.

Step-11. Apakah $\mathrm{B}_{[\mathrm{ij}]} \geq 0$,

- Jika ya, tulis $\mathrm{TC}_{\mathrm{ij}}$,

- Apakah $\mathrm{TC}_{\mathrm{ij}}<\mathrm{TC}_{(0)}$,

- Jika ya, seti $=\mathrm{i}+1$, lanjutkan ke step-9.

- Jika tidak atau tidak layak, set $\mathrm{k}=\mathrm{k}+1$, kembali ke step-5.

-Jika tidak, Solusi optimal tercapai, lanjutkan step-12.

Step-12. Tulis nilai fungsi tujuan dan semua nilai variabel keputusan.

\section{Numerical Experience}

Akan diberikan suatu contoh untuk melihat bagaimana algoritma ini bekerja. Misalkan jumlah part $\mathrm{q}=200$, waktu setup antar batch $\mathrm{s}=30$, waktu proses per part $\mathrm{t}=20$, panjang interval $\mathrm{PM}$ konstan $\mathrm{t}_{\mathrm{PM}}=60=\frac{1}{\mu}$, parameter $\beta=1,2$, parameter $\alpha=0,00035$, laju perbaikan konstan $\mu=\frac{1}{60}$, availabilitas target $\mathrm{A}=98 \%$, waktu penyerahan seluruh part $\mathrm{d}=5000, \mathrm{c}_{1}=20, \mathrm{c}_{2}=10, \mathrm{c}_{\mathrm{PM}}=600, \mathrm{c}_{\mathrm{s}}$ $=50$.

Solusi

Step-1 sampai step-3 memberikan $\mathrm{T}_{\min }=4000,4000+60<5000$, dan $\mathrm{N}_{\max }=34$, sehingga problem layak untuk model. Step-4 memberikan $x=2471,65$. Step-5 sampai 11 pada prinsipnya dimulai dengan satu production cycle dengan satu PM, selanjutnya tingkatkan jumlah batch pada satu production cycleini secara backward sampai diperoleh jumlah batch optimal ditandai dengan kenaikan 
total cost (TC) atau problem tidak layak. Kemudian dua production cycle dengan dua PM, dimulai dengan meningkatkan jumlah batch pada production cycle-1 kemudian production cycle-2 sampai terjadi kenaikanTC atau problem tidak layak. Proses ini dilanjutkan sampai diperoleh jumlah production cycle dan jumlah PM optimal dengan TC minimum.

SET production cycle $\mathrm{k}=1$, problem tidak layak, karena melanggar persamaan (34), di mana interval selang perawatan PM maksimum adalah 2471,65. adalah.

SET production cycle $\mathrm{k}=2$, berturut-turut untuk jumlah dan ukuran batch serta total biaya TC

\begin{tabular}{ccc}
\hline Jumlah batch PS-1 & Jumlah batch PS-2 & TC \\
\hline 1 & 1 & $1,01613 \times 10^{7}$ \\
\hline 2 & 1 & $9,76006 \times 10^{6}$ \\
\hline 3 & 1 & $9,69683 \times 10^{6}$ \\
\hline 4 & 1 & $9,71741 \times 10^{6}$ \\
& & TC naik, stop \\
\hline 1 & 2 & $9,69691 \times 10^{6}$ \\
\hline 1 & 3 & $9,56963 \times 10^{6}$ \\
\hline 1 & 4 & $9,52526 \times 10^{6}$ \\
\hline 1 & 5 & $9,52738 \times 10^{6}$ \\
& & TC naik, stop \\
\hline 2 & 2 & $9,28053 \times 10^{6}$ \\
\hline 2 & 3 & $9,14306 \times 10^{6}$ \\
\hline 2 & 4 & $9,08972 \times 10^{6}$ \\
\hline 2 & 5 & $9,16853 \times 10^{6}$ \\
& & TC naik, stop \\
\hline 3 & 2 & $9,20711 \times 10^{6}$ \\
\hline 3 & 3 & $9,06457 \times 10^{6}$ \\
\hline 3 & 4 & $9,00739 \times 10^{6}$ \\
\hline 3 & 5 & $8,98285 \times 10^{6}$ \\
\hline 3 & 6 & $9,12782 \times 10^{6}$ \\
& & TC naik, stop \\
\hline
\end{tabular}

SET production cycle $\mathrm{k}=3$, berturut-turut untuk jumlah dan ukuran batch serta total biaya TC adalah.

\begin{tabular}{rlll}
\hline Batch PS-1 & Batch PS-2 & Batch PS-3 & \multicolumn{1}{c}{ TC } \\
\hline 1 & 1 & 1 & $\begin{array}{l}9,67543 \times 10^{6} \\
\text { semakin naik, stop }\end{array}$ \\
\hline
\end{tabular}

Hasil optimal tercapai pada 2 production cycle dengan 2 PM dengan urutan dan ukuran batch serta waktu mulai pekerjaan dan waktu mulai dan berakhirnya PM sebagaimana Tabel 1 berikut

Tabel 1 Production cycle dengan 2 PM

\begin{tabular}{crrccc}
\hline $\mathbf{L}_{\mathrm{ij}}$ & $\mathbf{Q}_{\mathrm{ij}}$ & $\mathbf{B}_{\mathrm{ij}}$ & $\mathbf{A}_{\mathbf{P M}}$ & $\mathbf{B}_{\mathbf{P M}}$ & $\mathbf{T C}$ \\
\hline $\mathrm{Q}_{11}$ & 36,83 & 4263,33 & 5000,00 & 5060,00 & $8,98285 \times 10^{6}$ \\
\hline $\mathrm{Q}_{21}$ & 33,83 & 3556,67 & & & \\
\hline $\mathrm{Q}_{31}$ & 30,83 & 2910,00 & & & \\
\hline $\mathrm{Q}_{12}$ & 25,70 & 2306,00 & 2820,00 & 2880,00 & \\
\hline $\mathrm{Q}_{22}$ & 22,70 & 1822,00 & & & \\
\hline
\end{tabular}




\begin{tabular}{lll}
\hline $\mathrm{Q}_{32}$ & 19,70 & 1398,00 \\
\hline $\mathrm{Q}_{42}$ & 16,70 & 1034,00 \\
\hline $\mathrm{Q}_{52}$ & 13,70 & 730,00 \\
\hline
\end{tabular}

Dalam Gantt-Chart solusi optimal contoh dapat dilihat pada Gambar 4 berikut

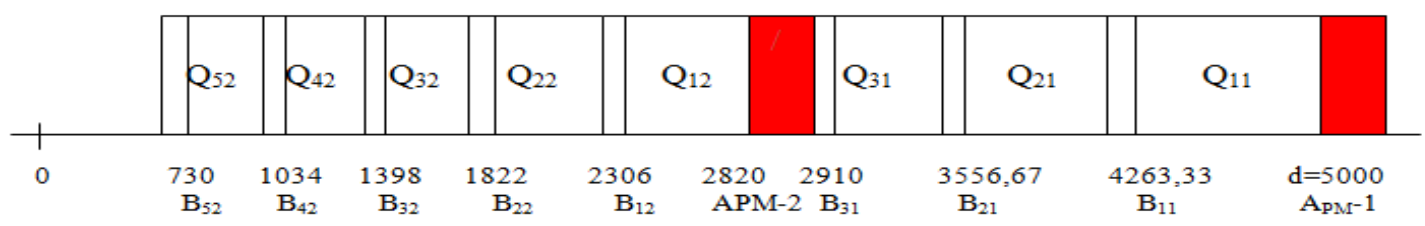

Gambar 4 Gantt-Chart solusi optimal contoh

\section{SIMPULAN}

Algoritma yang dikembangkan dapat menyelesaikan model dengan baik. Solusi optimal diperoleh dengan mengambil solusi optimal dari setiap step algoritma. Kaidah penjadwalan dengan kriteria minimasi waktu tinggal aktual terpenuhi disini, karena dari contoh dapat dilihat urutan batch yang mengikuti kaidah SPT (shortest processing time) atau non-icreasing secara backward.

Untuk kelanjutan penelitian, direkomendasikan untuk: (1) memasukkan aspek deteriorasi mesin, di mana proses bergeser dari status in control menjadi status out of control mengikuti suatu fungsi kerusakan mesin berdistribusi IFR Weibull, kemudian menghitung restoring cost untuk mengembalikan status mesin dari out of control menjadi in control (Lee \& Rosenblat (1987), Wang dan Sheu (2001), Tseng (1996), Ben-Daya dan Noman (2006), Lin dan Hou (2005), Chelbi dkk (2008), Makhdoum (1996), El-Ferik dan Ben-Daya (2010); (2) memasukkan aspek peluang kerusakan part pada status in control $\left(\mathrm{p}_{1}\right)$ dan peluang kerusakan pada status out of control $\left(\mathrm{p}_{2}\right)$, di mana $\mathrm{p}_{1}<\mathrm{p}_{2}$. Kemudian jumlah total partnon-conformingakan dikerjakan pada batch akhir, tepat sebelum due date (Indrapriyatna (2009)).

\section{DAFTAR PUSTAKA}

Ben-Daya, M. dan Noman, S. A. (2006). Lot Sizing, Preventive Maintenance and Warranty Decisions for Imperfect Production Systems. Journal of Quality in Maintenance Engineering, 12(1): 6880 .

Chelbi, A., Rezg, N., Radhoui, M. (2008). Simultaneous Determination of Production Lot Size And Preventive Maintenance Schedule for Unreliable Production System. Journal of Quality in Maintenance Engineering, 14(2): 161-176.

Disertasi Doktor tidak diterbitkan. University Osaka Perfecture, Japan.

Disertasi tidak diterbitkan. ITB, Bandung.

Duarte, J. C., Soares, C. G. (2007): Optimisation of Preventive Maintenance Plan of A Series Components System with Weibull Hazard Function. RTA, 4: 33-39. 
El-Ferik, S., Ben-Daya, M. (2010). Integrated Production Maintenance Model under Imperfect AgeBased Maintenance Policy and Non-Negligible Maintenace Times. Asia-Pacific Journal of Operational Research, 27(4): 539-558.

Halim, A. H. (1993). Batch Scheduling for Production Systems under Just in Time Environment.

Indrapriyatna, A. S. (2009). Model Penjadwalan Batch dengan Ketidaktersediaan Mesin untuk sistem Manufaktur Terdeteriorasi.

Kuo, Y., Chang, Z.A. (2007). Integrated Production Scheduling and Preventive Maintenance Planning for a SingleMachine Under a Cumulative Damage Failure Process. Naval Research Logistics, 54: 602-614.

Lee, C.H., dan Chen, Z.L. (1998). Scheduling of Jobs and Maintenance Activities on Parallel Machines, Naval Reseach Logistics.

Lee, H.L., dan Rosenblat, M.J. (1987). Simultaneous Determination of Production Cycle and Inspection Schedules in a Production System. Management Science, 33: 1125-1136.

Lin, L. C., Hou, K. L. (2005). EMQ Model with Maintenance Actions for Deteriorating Production System. Information and Management Sciences, 16(1): 53-65.

Makhdoum, M. A. A. (1996). Integrated Production, Quality And Maintenance Models under Various Preventive Maintenance Policies. ProQuest Dissertation and Thesis.

Sloan, T.W. dan Shantikumar, J.G. (2002). Using In-Line Equipment Condition and Yield Information for Maintemance Scheduling and Dispatching in Semiconductor Wafer Fabs. IIE Transaction, 34:191-209.

Sloan, T.W., dan Shantikumar, J.G. (2000). Conbined Production and Maintenance Scheduling for a Multiple-Products, Single Item Production System. Production and Operations Management, 9: 379-399.

Tseng, S.T. (1996). Optimal Preventive Maintenance Policy for Deteriorating Production Systems. IIE Transactions, 28: 687-694.

Wang, C.H., dan Sheu, S.H. (2001). Simultaneous Determination of the Optimal Production Inventory and Product Inspection Policies for a Deteriorating Production System. Computers \& Operations Research, 28: 1093 -1110. 